\title{
A comprehensive design of a structured technology-based therapy to prevent post intensive care syndrome (CogGYM platform)
}

\section{Mona M. El-Hady}

Emergency and Critical Care Nursing Department, Faculty of Nursing, Mansoura University, Egypt and

Emergency and Critical Care Nursing Department, Faculty of Nursing, King Abd-Alaziz University, Saudi Arabia Email: monamelhady@gmail.com

\section{Samaa M. Shohieb*}

Information Systems Department, Faculty of Computers and Information, Mansoura University, Egypt

Email: sm_shohieb@mans.edu.eg

*Corresponding author

\begin{abstract}
Post-intensive care syndrome (PICS) is a newly acquired long-term cognitive impairment. It includes major physical, mental and functional disabilities that affect the critically ill patients' experience This paper presents a complete research design (from medical and technical points of views), test conduction, and evaluate the effect of implementing a designed structured technology-based therapy (STBT) on preventing PICS among critically ill patients. Authors called the new STBT platform, cognition gymnastics (CogGym). CogGym is an android-based devices platform with an Arabic user interface (UI) that contains many flexible and easy to use games designed specifically for the Arab critically ill patients. In conclusion, CogGym enables them to continue to do therapeutic gymnastics after the therapist leaves the room to keep working toward rehabilitation goals.
\end{abstract}

Keywords: cognition games; critically ill patients; intensive care unit; ICU; post-intensive care syndrome; PICS; technology-based therapy.

Reference to this paper should be made as follows: El-Hady, M.M. and Shohieb, S.M. (2020) 'A comprehensive design of a structured technology-based therapy to prevent post intensive care syndrome (CogGYM platform)', Int. J. Entertainment Technology and Management, Vol. 1, No. 1, pp.80-94.

Biographical notes: Mona M. El-Hady is a Professor Assistant in the Faculty of Nursing, Emergency and Critical Care Nursing Department at the Mansoura University, Egypt. She received her Master's and PhD. She has many publications and books in human science, evidence based and medical informatics. 
Samaa M. Shohieb is a Professor Assistant in the Faculty of Computer Science and Information Systems Department at the Mansoura University, Egypt. She received her Master's and $\mathrm{PhD}$. She is a reviewer in many international journals including Elsevier. She is an editorial board member in two international journals. She is interested in human-computer interaction integrated with e-society and designing creative ICT solutions for diverse users with specified capabilities. She has many publications and books in this area.

This paper is a revised and expanded version of a paper entitled 'CogGym games: a structured technology based therapy to prevent post intensive care syndrome among critically ill patients' presented at MCCSIS 2018 - Multi Conference on Computer Science and Information Systems; Proceedings of the International Conferences on e-Health 2018, ICT, Society, and Human Beings 2018 and Web Based Communities and Social Media 2018, Madrid, Spain, 17-20 July 2018.

\section{Introduction}

Yearly, millions of critically ill patients experience newly acquired long-term cognitive impairment and major physical, mental and functional disabilities (Jackson et al., 2012; Kara and Ntsiea, 2015). Those patients are given the diagnosis of post-intensive care syndrome (PICS). PICS is known as an impairment or deterioration in cognitive (e.g., judgment and thinking), physical [e.g., intensive care unit (ICU)-acquired neuromuscular weakness], or mental functions developing after acute disorders and continue beyond the critical care setting discharge (Needham et al., 2012; Parker et al., 2013; Robinson, 2013).

The main risk factors relevant to PICS include delirium duration in ICU, acute brain disorders (e.g., alcoholism, stroke), hypoxic status [due to acute respiratory distress syndrome (ARDS) or cardiac arrest], hypotension (involving severe sepsis and trauma), glucose deregulation, prolonged mechanical ventilation (MV) needed to correct respiratory failure, use of renal replacement therapy, and past history of cognitive impairment combined with advanced age, pre-existing cognitive deficits, or pre-morbid health conditions (Davydow et al., 2012; Carlson and Huang, 2013; Rawal et al., 2017; Iwashyna et al., 2010; Mikkelsen et al., 2012).

Patients with PICS can experience different limitations and disabilities that are usually difficult to recognise. PICS related limitations can be apparent in the form of neuromuscular dysfunction, or less evident, like mild cognitive impairments (Jean et al., 2010; Robinson, 2013). PICS often persist beyond acute care hospitalisation, and may last for months or years after hospital discharge affecting patient's quality of life (Aberegg, 2005; Parker et al., 2013; Lin et al., 2012).

PICS is recently recognised as a public health burden associated with neuropsychological and functional impairments, however its exact prevalence is still vague (Rawal et al., 2017; Wergin and Modrykamien, 2012). Cognitive impairment has been documented to occur in more than 75\% of ICU survivors (Needham et al., 2013; Pandharipande et al., 2014; Davydow, 2013). Literature has demonstrated that the risk of developing psychological impairment after ICU discharge, ranges from 1 to $62 \%$ and 
ICU-acquired neuromuscular weakness is developing in more than $25 \%$ of ICU survivors (Fan et al., 2014a, 2014b; Hermans et al., 2014; Hoffmann and Tornatore, 2009).

Preventing PICS is better than cure. The most important preventive strategies which have a positive impact on preventing the PICS related long-term functional impairments involve reducing deep sedation used and encouraging critically ill patient's early mobility, concomitant with aggressive physical and occupational management. A multidisciplinary approach is recommended for the best outcome and successful management of these strategies (Balas et al., 2014; Kress, 2013; Schweickert et al., 2009; Morandi et al., 2011).

Mobile phones are no longer a luxury item. Every adult, as well as children, may have one or more mobile phones. Based on these developments, advanced technology as tablet and smart mobile phones are considered a successful alternative method to assist occupational therapy practitioners for completing therapeutic activities in the ICU setting (Needham et al., 2009, 2010; ClinicalTrials.gov, 2018). Tablet is already being used as a tool for patient management in school systems and outpatient rehabilitation facilities through encouraging social participation, communication, motor planning, fine motor coordination, and sensory perception (Hoesterey and Chappelle, 2012; Waite, 2012). However, there are very limited studies all over the world in general, and in Arab world specifically, that investigate the benefits of using this therapy on critically ill patients.

CAM-ICU is a platform that helps in assessing cognition early in the health journey of the critically ill patients. It helps to plan treatment and allow patients to back to their majority of functional level of independence in their daily occupations (Lober and Walker, 2016). Baysari et al. (2014) integrated Ipad-based activities with the occupational therapy sessions. Erickson (2015) also implemented a mobile Aapp-based device that was incorporated in the occupational therapy process.

Egypt, as a developing country characterised by elevated poverty incidence rate more than 30\% (UNICEF, 2018; Al-Masry Al-Youm, 2018, The Middle East Monitor, 2009-2018; Egypt Independent, 2018) that results in a low foreign language culture for the general population. Until now, there is no research that studies this technology in ICUs in the Arab world. STBT is defined as a mobile-based cognitive training intervention that is used to prevent physical, cognitive and psychological impairments. Consequently, this paper presents cognition gymnastics (CogGym), which is an androidbased platform with an Arabic UI that contains many flexible and easy to use games designed specifically to prevent PICS among the Arab critically ill patients. Consequently, CogGym enables them to continue to do therapeutic gymnastics after the therapist leaves the room to keep working toward rehabilitation goals.

\section{Methodologies and experimental design}

This work presents a complete research design, implementation, and evaluation of a STBT to prevent PICS among critically ill. This research aims to evaluate the effect of implementing a STBT on preventing PICS among critically ill patients. It was achieved through implementing CogGym platform, and testing it with a sample of ICU patients. Accordingly, the null hypothesis states that there is no statistically significant difference in ICU patients' improvement when they receive STBT. The first hypothesis (H1) claims that technology-based therapy will maintain neuro-cognitive capabilities and prevent long-term cognitive impairment among critically ill patients. The second hypothesis $(\mathrm{H} 2)$ 
claims that technology-based therapy will reduce psychological disability among critically ill patients. The third hypothesis (H3) claims that technology-based therapy will eliminate incidence rate of ICU-acquired neuromuscular weakness. The methodology that we followed consists of the following steps.

\subsection{Research design and setting}

A quasi-experimental design will be used to achieve the aim of the current study. A quasi-experimental design is one of experimental design that is very similar to the true-experimental design expect there is lose one criteria, randomisation or control. The study will be performed in respiratory and postoperative ICUs at Mansoura University Hospital, Mansoura, Egypt.

\subsection{Sample selection}

Convenience sampling technique will be used for patient recruitment during the current study. A 120 patients admitting to the predetermined setting have been enrolled in the study. The sample size was estimated by using the epidemiological information (EPI info) program with confidence coefficient at $90 \%$. The sample will be divided into four groups (30 patients in each group); group A (control group who will receive the routine hospital care to prevent PICS); group B (patients receiving STBT); group C (patients receiving pharmacological therapy to prevent PICS) and group D (patients receiving STBT and pharmacological therapy)

The newly admitted patients to ICU, who is mechanically ventilated, alert (Glasgow coma scale, GCS $\geq 12$ ) hemodynamically stable and normoglycemia will be included in the study. The studied patients must have some form of active range of motion in at least one upper extremity, and be able to read and write (Djabelkhir et al., 2017; Malinowsky et al., 2015). While, patients who are not able to follow the instructions to perform the program, such as patients with delirium, visual or auditory deficit, and cognitive impairment will be excluded from the study. Also, patients with movement limitations like spinal disorders, short-term mortality or admitted after a cardiac arrest, will be excluded (Regensburg, 2014; Erickson, 2015).

\subsection{Research tools}

Three tools have been used by the researchers after reviewing updated literature review to collect the data for the study.

\subsubsection{Tool (I) 'post ICU syndrome assessment sheet'}

This tool is developed by the researchers to collect data about sociodemographic and clinical characteristics and pulmonary function parameters. It included two parts:

- Part one 'patient's profile data'

This part will be developed to gather data about socio-demographic (patient's age, gender, marital status, educational levels, and occupation) and clinical characteristics (diagnosis, past history, acute physiology and chronic health evaluation II (APACHE) score, GCS). 
- Part two 'pulmonary function parameters'

This part will be developed to assess pulmonary function capabilities such as reason for mode and duration of MV, types of MV, length of ICU stay, length of hospital stay, type of discharge, adverse events developed during hospitalisation.

\subsubsection{Tool (II) 'cognitive stimulator observation sheet'}

This tool was developed by the researchers to collect data about the received medications that can affect patient's neuro-cognitive functions includes sedatives, analgesics, cognitive stimulators, cognitive inhibitors, mood stabilisers.

\subsubsection{Tool (III) 'STBT outcome follow up sheet'}

This tool was developed by the researchers to collect data about patient's outcomes to STBT practices. It will be arranged in follow up sheet that include two time observations for cognitive capabilities using (Johns Hopkins adapted cognitive exam), delirium using cognitive assessment method-ICU, sedation score using Richmond agitation sedation scale, psychological impairment using hospital anxiety and depression scale, upper extremities muscle strength by using medical research council manual muscle testing scale, vital signs (temperature, heart rate, respiratory rate, blood pressure), oxygen saturation, end tidal carbon dioxide, central venous pressure, ventilation mode, fracture inspired oxygen and blood glucose level.

\subsection{Ethical considerations}

An ethical approval is obtained from the ethics committee of Faculty of Nursing, Mansoura University. An informed consent will be obtained from patients who accepted to participate in the study after providing detailed description of the aim, the procedure of the study, risks and benefits. All subjects will be assured that participant in the study is voluntary and that refusing to take part in the study did not affect their treatment or care. Data confidentiality will be maintained.

\section{The proposed 'CogGym' platform}

The CogGym game is categorised as an assistive technology that runs on android-based devices (mobiles or tablets), whose aim is preventing physical, cognitive and psychological impairments among critically ill patients.

\subsection{CogGym design}

In the development of our system, authors used ergonomics of human-system interaction - part 210: human-centred design for interactive systems (ISO.Org, 2018) to design CogGym (Figure 1). 
Design methodology was as follows:

a What is wanted and problem identification (user experience research):

Actions conducted by researchers in identifying the problem are:

1 Conducting personal interviews with ICU doctors.

2 Conducting field observation (observing critically ill patients' activities in the open field.)

3 Collecting and analysis of related research literature.

b Analysis phase: researchers analysed the findings that are available in Egypt, as one of the developing countries. It is very difficult (economically) for the ICU staff to maintain and preserve the critically ill patients from the PICS. Consequently, researchers established their goals in developing a game to solve the mentioned valuable issues.

c Design phase: in this process we began the software development and prototyping for the platform. That was made in terms of construction models and methods. We began with to sketching the game as a paper-based prototype, then building the algorithm.

d Implementation and deployment phase: the next stage, was defining the major features of the game. On the other hand, researchers designed the prototype interface to be displayed on a full screen of a mobile or a tablet device. Also, a tutorial is used to simulate every feature's functionality and demonstrate the main countenances to both the patient and the caregivers for assuring that countenances satisfied their expectations.

Figure 1 HCI-based design process (see online version for colours)

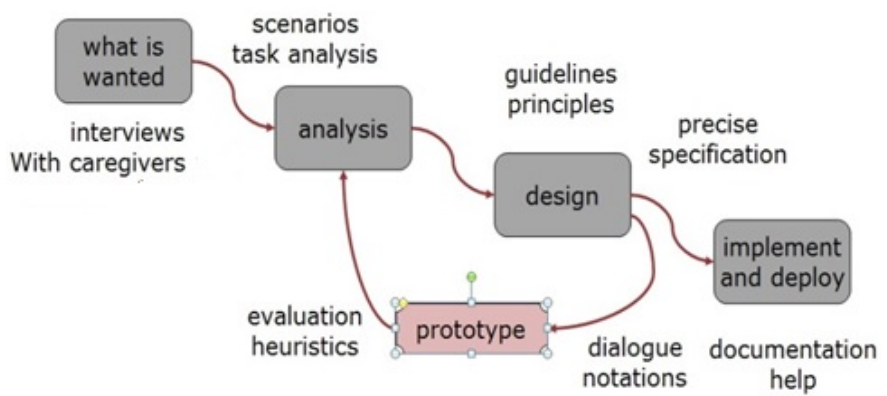

\subsection{CogGym specification and description}

The entire CogGym platform interface is in Arabic language. CogGym contains ten sub-games that are used to enhance the ten different perceptions capabilities for each person as addressed in literature (Lin et al., 2012; Malinowsky et al., 2015; Kara and Ntsiea, 2015; Rubrics and Fun, 2018) that are defined in Table 1. 
Table 1 Different perceptions capabilities for each person

\begin{tabular}{|c|c|c|}
\hline \# & $\begin{array}{l}\text { Perception } \\
\text { capability }\end{array}$ & Definition \\
\hline 1 & $\begin{array}{c}\text { Visual } \\
\text { discrimination }\end{array}$ & $\begin{array}{l}\text { Visual discrimination is defined as the capability to recognise } \\
\text { differences and similarities between size, shapes, colours, patterns and } \\
\text { objects. The ability to determine differences and similarities between } \\
\text { objects helps us to understand and interpret the environment around us. }\end{array}$ \\
\hline 2 & $\begin{array}{l}\text { Figure ground } \\
\text { perception }\end{array}$ & $\begin{array}{l}\text { Figure ground perception is the capability to refine visual information } \\
\text { that is not important so that person can focus on the relevant visualised } \\
\text { information. This allows people to find the detailed visual information } \\
\text { even when it is part of a busy background. }\end{array}$ \\
\hline 3 & Form constancy & $\begin{array}{l}\text { Form constancy is defined as a visual perceptual skill that allows } \\
\text { person to understand that an object, shape, form stays the same even } \\
\text { when it changes in size, position or is in a different environment. For } \\
\text { example, when you see the letter 'A' it is always the letter 'A' whether } \\
\text { in a word, in bigger text or different font - CAT, CAT or CAT. }\end{array}$ \\
\hline 4 & Visual closure & $\begin{array}{l}\text { Visual closure is a visual perceptual skill that allows person to know } \\
\text { what an object is even when the object is only partially visible. } \\
\text { Example, is reading words together instead of every letter at a time. }\end{array}$ \\
\hline 5 & Visual memory & $\begin{array}{l}\text { Is the capability to straightaway consider what the eye has seen? This } \\
\text { ability permits us to consider what a shape, image, item or shape gave } \\
\text { the impression of which is essential for studying and activities of each } \\
\text { day living. }\end{array}$ \\
\hline 6 & $\begin{array}{l}\text { Visual } \\
\text { sequential } \\
\text { memory }\end{array}$ & $\begin{array}{l}\text { Is the potential to take into account and recall a series of objects and/or } \\
\text { occasions in the suitable order? The potential to do not forget what } \\
\text { order wherein we see objects is crucial when gaining knowledge of the } \\
\text { basics of literacy and math. }\end{array}$ \\
\hline 7 & $\begin{array}{l}\text { Visual spatial } \\
\text { relationship }\end{array}$ & $\begin{array}{l}\text { Is the capacity to visually understand two or more items on the subject } \\
\text { of each other }\end{array}$ \\
\hline 8 & $\begin{array}{l}\text { Visual motor } \\
\text { integration }\end{array}$ & $\begin{array}{l}\text { Is the potential to interpret visible statistics and respond with motor } \\
\text { actions }\end{array}$ \\
\hline 9 & Visual tracking & $\begin{array}{l}\text { IT's typically defined as the ability to efficiently move the eyes from } \\
\text { left to right (or right to left, up and down, and circular motions) OR } \\
\text { focusing on an object as it moves across a person's visual field. This } \\
\text { skill is important for almost all daily activities, including reading, } \\
\text { writing, cutting with scissors, drawing, and playing. There are two } \\
\text { varieties of visual monitoring: preserving your attention on transferring } \\
\text { item and switching your attention among objects }\end{array}$ \\
\hline 10 & Visual focus & $\begin{array}{l}\text { Visual focus is the capability to see things clearly. The ability to focus } \\
\text { is sometimes referred to as accommodation. When we look at objects, } \\
\text { the lens of the eye need to change shape to bring the object into focus. }\end{array}$ \\
\hline
\end{tabular}

The first level is always a training level to teach the player how to play the game. After completing each level there is a soft sound of clapping to motivate the player and inform him that he has completed the level successfully. CogGym has not any disturbing noisy sounds or background music to not disturb or/and de-concentrate the patient. The main screen of CogGym has four buttons (Figure 2) namely:

a Play button: this button is specified for patient to start playing and do the practicing process. 
b Caregiver button: this allows therapists and caregivers to follow the patients' improvements and overall performances along the time. The overall information for the caregivers to assess his/her patient is: (patient's name, last level that the patient arrived, number of levels played, number of times to win, number of times to loose, number of icons, best score in the time-based level, time of starting last play and time of ending, total time for the last level, total time in playing the game, the percentage of winning times, longest time spent in a level, and shortest time spent in a level).

Also, the caregiver can do the following from their control panel after some verification.

- change the patient's name

- choose the types of icons that he needs his patient to learn (selected form the ten types).

c About us button: that contains general information and data about the game's designers.

d Exit button: to exit form the game.

Figure 2 Main screen of CogGym (see online version for colours)

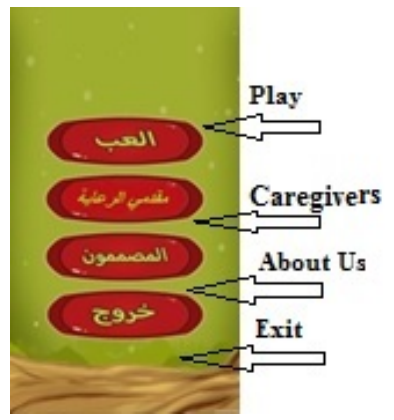

\subsection{CogGym elements}

There are nine major game elements (Nacke, 2018) (that should be included with all games). These elements involve:

- Players: the game we have developed is single player. The player can choose any type of the 11 games included and try to solve it. The game is not competitive.

- Game procedures: the outset action of the game requires every player to gain the required knowledge to win. The progressive action is to handle the increasing requirements and complexity.

- Objectives: the game has a main objective that is preventing PICS for the critically ill patients

- Probability: probability is defined as distribution for designated different perceptions capabilities that targeted to be practiced. 
- Rules: some levels are timed to control the game flow. If a one's time runs out, he/she will be prohibited to continue with the game play. There are virtual commands during the level to define what must be done for the player.

- Resources: the resources are to use the available time and environmental aids to complete the tasks.

- Boundary: the game area is restricted to the board of the game.

- Conflict: players (patients) indigence to identify relevant information to determine the task objectives.

- Game outcome: scoring criteria was pre-defined to determine how every player understands the concepts at play and to control the game play well. The outcome of the game is closed ended.

\subsection{CogGym platform games}

Table 2 contains the ten different perceptions capabilities for each person with the corresponding CogGym designed game for practicing this capability.

Table 2 Perceptions capabilities with the corresponding CogGym platform (see online version for colours)

\begin{tabular}{|c|c|c|c|c|}
\hline \# & Perception capability & Game name & Skill description & CogGym game examp \\
\hline \multirow[t]{5}{*}{1} & \multirow[t]{5}{*}{ Visual discrimination } & \multirow[t]{5}{*}{$\begin{array}{l}\text { Shapes } \\
\text { rotation }\end{array}$} & \multirow[t]{5}{*}{$\begin{array}{l}\text { The skill of } \\
\text { progress as } \\
\text { conditions } \\
\text { change and shift } \\
\text { from one goal } \\
\text { to another. }\end{array}$} & 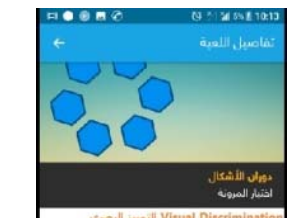 \\
\hline & & & & 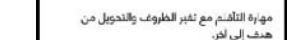 \\
\hline & & & & 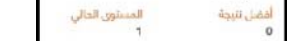 \\
\hline & & & & | \\
\hline & & & & - \\
\hline \multirow[t]{9}{*}{2} & \multirow{9}{*}{$\begin{array}{l}\text { Figure ground } \\
\text { perception }\end{array}$} & \multirow{9}{*}{$\begin{array}{l}\text { Different } \\
\text { Shape }\end{array}$} & \multirow{9}{*}{$\begin{array}{l}\text { The skill to } \\
\text { focus on } \\
\text { important } \\
\text { information and } \\
\text { avoid dispersion } \\
\text { in the side. }\end{array}$} & 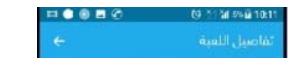 \\
\hline & & & & $D D$ \\
\hline & & & & 0 \\
\hline & & & & 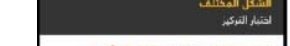 \\
\hline & & & & 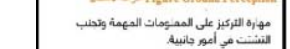 \\
\hline & & & & 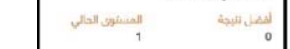 \\
\hline & & & & 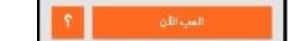 \\
\hline & & & & 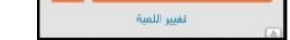 \\
\hline & & & & $4 \quad \bullet$ \\
\hline
\end{tabular}


Table 2 Perceptions capabilities with the corresponding CogGym platform (continued) (see online version for colours)

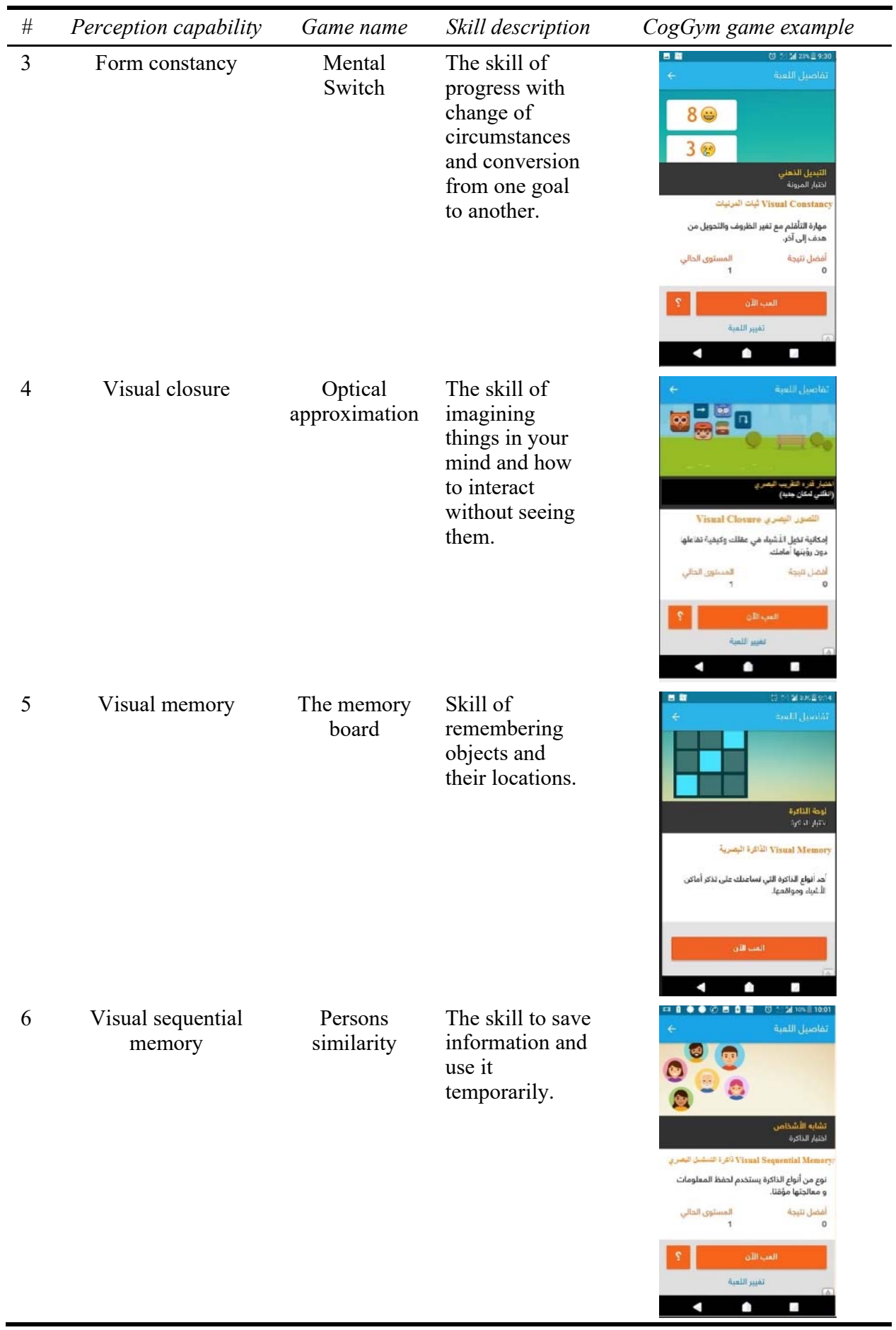


Table 2 Perceptions capabilities with the corresponding CogGym platform (continued) (see online version for colours)

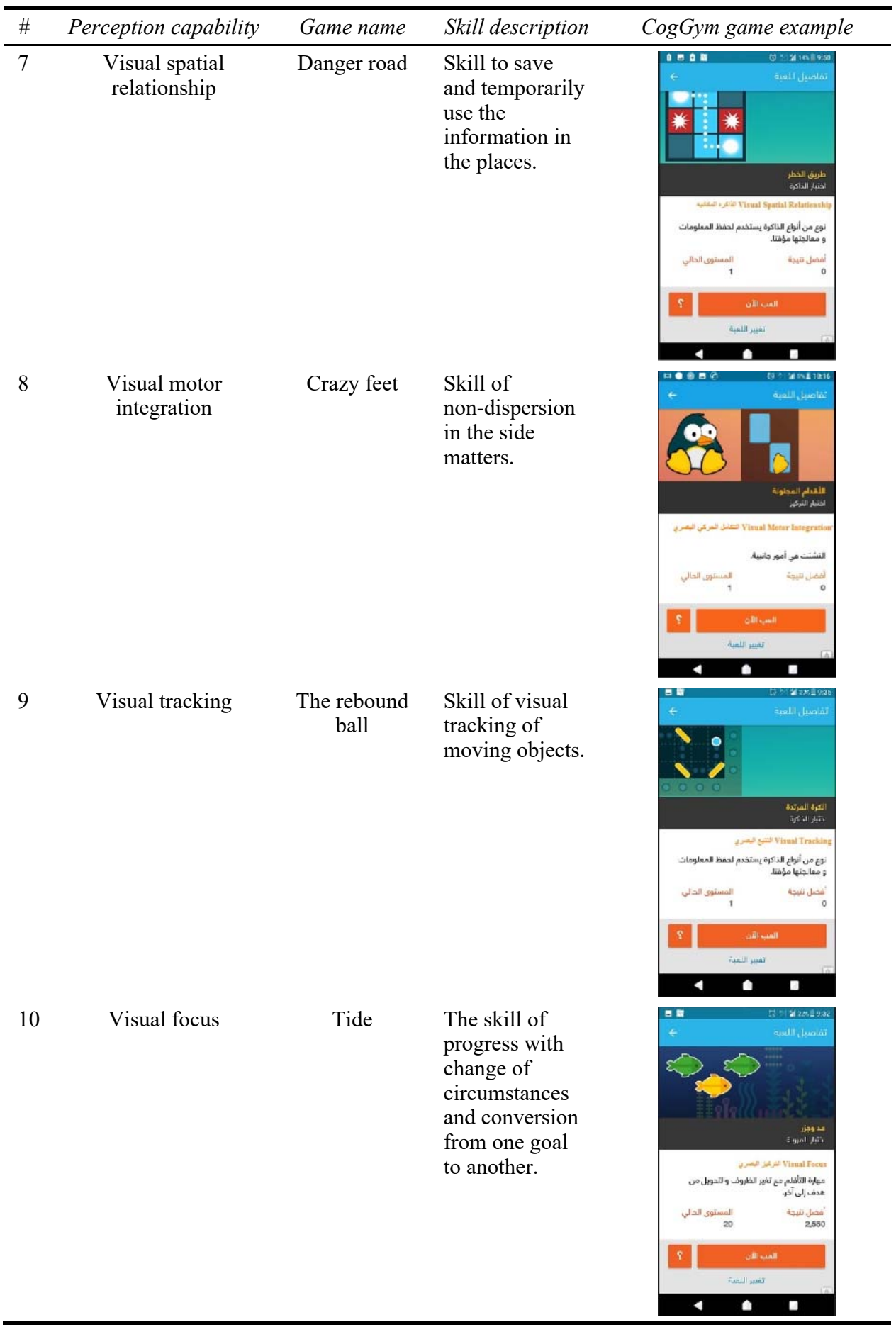




\section{Conclusions and future work}

Critically ill patients usually suffer some degree of decline in their cognitive capacities (such as decreased problem solving to maintain focus, forgetfulness and decreased ability to reason, etc.). Those patients are given the diagnosis of PICS. Technology-based therapy provides new training chances to improve the deterioration in cognitive functions. This paper also gives details on the design of CogGym platform. CogGym contains serious games with Arabic UI helping to train planning, memory, attention and reasoning. CogGym has been designed as a STBT to prevent PICS among Arab critically ill patients. This paper also contains a complete medical proposal to deploy CogGym on patients in Mansoura University hospitals in Egypt.

The application of SCST will be applied for the critical ill patients and feedbacks are going to be collected, analysed and discussed to enhance the application usability for achieving the most benefits for this type of patients.

\section{References}

Aberegg, S. (2005) 'Two-year cognitive, 'emotional, and quality-of-life outcomes in acute respiratory distress syndrome', American Journal of Respiratory and Critical Care Medicine, Vol. 172, No. 6, pp.786-786.

Al-Masry Al-Youm (2016) UNICEF: $30 \%$ Poverty Rate in Egypt, July [online] https://www.egyptindependent.com/278-percent-egyptian-population-lives-below-povertyline-capmas/ (accessed 1/10/2018).

Balas, M., Vasilevskis, E., Olsen, K., Schmid, K., Shostrom, V., Cohen, M., Peitz, G., Gannon, D., Sisson, J., Sullivan, J., Stothert, J., Lazure, J., Nuss, S., Jawa, R., Freihaut, F., Ely, E. and Burke, W. (2014) 'Effectiveness and safety of the awakening and breathing coordination, delirium monitoring/management, and early exercise/mobility bundle', Critical Care Medicine, Vol. 42, No. 5, pp.1024-1036.

Baysari, M.T., Adams, K., Lehnbom, E.C., Westbrook, J.I. and Day, R.O. (2014) 'Ipad use at the bedside: a tool for engaging patients in care processes during ward rounds?', Internal Medicine Journal, Vol. 44, No. 10, pp.986-990, DOI: 10.1111/imj.12518.

Carlson, C. and Huang, D. (2013) 'The adult respiratory distress syndrome cognitive outcomes study: long-term neuropsychological function in survivors of acute lung injury', Critical Care, Vol. 17, No. 3, p.317.

ClinicalTrials.gov (2018) ACT-ICU Study: Activity and Cognitive Therapy in the Intensive Care Unit - Full Text View, Clinicaltrials.Gov. [online] http://clinicaltrials.gov/ct2/show/ NCT01270269 (accessed 16 December 2018).

Davydow, D., Hough, C., Langa, K. and Iwashyna, T. (2012) 'Presepsis depressive symptoms are associated with incident cognitive impairment in survivors of severe sepsis: a prospective cohort study of older Americans', Journal of The American Geriatrics Society, Vol. 60, No. 12, pp.2290-2296.

Davydow, D., Zatzick, D., Hough, C. and Katon, W. (2013) 'In-hospital acute stress symptoms are associated with impairment in cognition 1 year after intensive care unit admission', Annals of The American Thoracic Society, Vol. 10, No. 5, pp.450-457.

Djabelkhir, L., Wu, Y., Vidal, J., Cristancho-Lacroix, V., Marlats, F., Lenoir, H., Carno, A. and Rigaud, A. (2017) 'Computerized cognitive stimulation and engagement programs in older adults with mild cognitive impairment: comparing feasibility, acceptability, and cognitive and psychosocial effects', Clinical Interventions in Aging, Vol. 12, No. 1, pp.1967-1975. 
Egypt Independent (2018) 278-Percent of Egyptian Population Lives below Poverty Line: CAPMAS - Egypt Independent [online] https://www.egyptindependent.com/278-percentegyptian-population-lives-below-poverty-line-capmas/ (accessed 16 December 2018).

Erickson, K. (2015) 'Evidence considerations for mobile devices in the occupational therapy process', The Open Journal of Occupational Therapy, Vol. 3, No. 2, pp.1-14.

Fan, E., Cheek, F., Chlan, L., Gosselink, R., Hart, N., Herridge, M., Hopkins, R., Hough, C., Kress, J., Latronico, N., Moss, M., Needham, D., Rich, M., Stevens, R., Wilson, K., Winkelman, C., Zochodne, D. and Ali, N. (2014b) 'An official American thoracic society clinical practice guideline: the diagnosis of intensive care unit-acquired weakness in adults', American Journal of Respiratory and Critical Care Medicine, Vol. 190, No. 12, pp.1437-1446.

Fan, E., Dowdy, D., Colantuoni, E., Mendez-Tellez, P., Sevransky, J., Shanholtz, C., Dennison Himmelfarb, C., Desai, S., Ciesla, N., Herridge, M., Pronovost, P. and Needham, D. (2014a) 'Physical complications in acute lung injury survivors', Critical Care Medicine, Vol. 42, No. 4, pp.849-859.

Hermans, G., Van Mechelen, H., Clerckx, B., Vanhullebusch, T., Mesotten, D., Wilmer, A., Casaer, M., Meersseman, P., Debaveye, Y., Van Cromphaut, S., Wouters, P., Gosselink, R. and Van den Berghe, G. (2014) 'Acute outcomes and 1-year mortality of intensive care unit-acquired weakness. A cohort study and propensity-matched analysis', American Journal of Respiratory And Critical Care Medicine, Vol. 190, No. 4, pp.410-420.

Hoesterey, C. and Chappelle, C. (2012) 'Touch the future: using iPads as a therapeutic tool', OT Practice, Vol. 17, No. 13, pp.7-9.

Hoffmann, T. and Tornatore, G. (2009) 'Early physical and occupational therapy in mechanically ventilated, critically ill patients resulted in better functional outcomes at hospital discharge', Australian Occupational Therapy Journal, Vol. 56, No. 6, pp.438-439.

ISO.Org (2018) ISO 9241-210 [online] https://www.iso.org/obp/ui/\#iso:std:iso:9241:-210:ed1:v1:en (accessed 16 December 2018).

Iwashyna, T., Ely, E., Smith, D. and Langa, K. (2010) 'Long-term cognitive impairment and functional disability among survivors of severe sepsis', JAMA, Vol. 304, No. 16, p.1787.

Jackson, J., Ely, E., Morey, M., Anderson, V., Denne, L., Clune, J., Siebert, C., Archer, K., Torres, R., Janz, D., Schiro, E., Jones, J., Shintani, A., Levine, B., Pun, B., Thompson, J., Brummel, N. and Hoenig, H. (2012) 'Cognitive and physical rehabilitation of intensive care unit survivors', Critical Care Medicine, Vol. 40, No. 4, pp.1088-1097.

Jean, L., Bergeron, M., Thivierge, S. and Simard, M. (2010) 'Cognitive intervention programs for individuals with mild cognitive impairment: systematic review of the literature', The American Journal of Geriatric Psychiatry, Vol. 18, No. 4, pp.281-296.

Kara, S. and Ntsiea, M. (2015) 'The effect of a written and pictorial home exercise prescription on adherence for people with stroke', Hong Kong Journal of Occupational Therapy, Vol. 26, No. 1, pp.33-41.

Kress, J.P. (2013) 'Sedation and mobility: changing the paradigm', Crit Care Clin., Vol. 29, No. 1, pp.67-75.

Lin, C., Su, C. and Ma, H. (2012) 'Physical activity patterns and quality of life of overweight boys: a preliminary study', Hong Kong Journal of Occupational Therapy, Vol. 22, No. 1, pp.31-37.

Lober, G. and Walker, R. (2016) 'An effective cognition assessment in ventilated patients' occupational therapy', Graduate Student Evidenced-Based Research Reviews, Vol. 12, No. 2, pp.56-62.

Malinowsky, C., Kottorp, A., Tanemura, R., Asaba, E., Nagao, T., Noda, K., Sagara, J., Bontje, P., Rosenberg, L. and Nygård, L. (2015) 'Validation of the everyday technology use questionnaire in a Japanese context', Hong Kong Journal of Occupational Therapy, Vol. 26, No. 1, pp.1-8. 
Mikkelsen, M.E., Christie, J.D., Lanken, P.N., Biester, R.C., Thompson, B.T. and Bellamy, S.L. (2012) 'The adult respiratory distress syndrome cognitive outcomes study: long-term neuropsychological function in survivors of acute lung injury', Am J Respir Crit Care Med., Vol. 185, pp.1307-1315.

Morandi, A., Brummel, N.E. and Ely, E.W. (2011) 'Sedation, delirium and mechanical ventilation: the 'ABCDE' approach', Curr. Opin. Crit. Care, Vol. 17, No. 1, pp.43-49.

Nacke, L. (2018) Dramatic Elements of Games and Narrative Design, The Acagamic [online] http://www.acagamic.com/courses/infr1330-2014/dramatic-elements-of-games-and-narrativedesign/ (accessed 16 December 2018).

Needham, D., Truong, A. and Fan, E. (2009) 'Technology to enhance physical rehabilitation of critically ill patients', Critical Care Medicine, Vol. 37, No. 10, pp.S436-S441.

Needham, D.M., Davidson, J., Cohen, H., Hopkins, R.O., Weinert, C., Wunsch, H., Zawistowski, C., Bemis-Dougherty, A., Berney, S.C., Bienvenu, O.J., Brady, S.L., Brodsky, M.B., Denehy, L., Elliott, D., Flatley, C., Harabin, A.L., Jones, C., Louis, D., Meltzer, W., Muldoon, S.R., Palmer, J.B., Perme, C., Robinson, M., Schmidt, D.M., Scruth, E., Spill, G.R., Storey, C.P., Render, M., Votto, J. and Harvey, M.A. (2012) 'Improving long-term outcomes after discharge From intensive care unit: report from a stakeholders', Conference, Crit. Care Med., Vol. 40, No. 2, pp.502-509, DOI: 10.1097/ CCM.0b013e318232da75.

Needham, D.M., Dinglas, V.D., Morris, P.E., Jackson, J.C., Hough, C.L. and Mendez-Tellez, P.A. (2013) 'Physical and cognitive performance of patients with acute lung injury 1 year after initial trophic versus full enteral feeding Eden trial follow-up', Am. J. Respir. Crit. Care Med., Vol. 188, No. 5, pp.567-576, DOI: 10.1164/rccm.201304-0651OC.

Needham, D.M., Korupolu, R., Zanni, J.M., Pradhan, P., Colantuoni, E., Palmer, J.B. and Fan, E. (2010) 'Early physical medicine and rehabilitation for patients with acute respiratory failure: a quality improvement project', Archives of Physical Medicine and Rehabilitation, Vol. 19, No. 4, pp.536-542, DOI: 10.1016/j.apmr.2010.01.002.

Pandharipande, P.P., Girard, T.D., Jackson, J.C., Morandi, A., Thompson, J.L. and Pun, B.T. (2014) 'Long-term cognitive impairment after critical illness', New England Journal of Medicine, Vol. 370, No. 2, pp.184-186.

Parker, A., Sricharoenchai, T. and Needham, D. (2013) 'Early rehabilitation in the intensive care unit: preventing impairment of physical and mental health', Current Physical Medicine and Rehabilitation Reports, Vol. 1, No. 4, pp.307-314.

Rawal, G., Yadav, S. and Kumar, R. (2017) 'Post-intensive care syndrome: an overview', Journal of Translational Internal Medicine, Vol. 5, No. 2, pp.90-92.

Regensburg, A.M. (2014) 'Use of iPads by occupational therapists in a medical intensive care unit', Physical Disabilities, Vol. 37, No. 3, pp.1-4.

Robinson, M.R. (2013) 'Post intensive care syndrome: the important implications for occupational therapy practitioners', OT Practice, Vol. 18, No. 13, pp.7-9.

Rubrics, H. and Fun, R. and (2018) Your Therapy Source, OT/PT, Therapists [online] https://www.yourtherapysource.com/ (accessed 16 December 2018).

Schweickert, W.D., Pohlman, M.C., Pohlman, A.S., Nigos, C., Pawlik, A.J., Esbrook, C.L., Spears, L., Miller, M., Franczyk, M., Deprizio, D., Schmidt, G.A., Bowman, A., Barr, R., McCallister, K.E., Hall, J.B. and Kress, J.P. (2009) 'Early physical and occupational therapy in mechanically ventilated, critically ill patients: a randomised controlled trial', Lancet, Vol. 373, pp.1874-1882.

The Middle East Monitor (2018) 27.8 Percent of Egyptian Population Lives Below Poverty Line: CAPMAS, January [online] https://www.middleeastmonitor.com/20180110-unicef-30-povertyrate-in-egypt/ (accessed 1/10/2018). 
UNICEF (2018) 30\% Poverty Rate in Egypt, Middle East Monitor [online] https://www.middleeastmonitor.com/20180110-unicef-30-poverty-rate-in-egypt/ (accessed 16 December 2018).

Waite, A. (2012) 'AppTitude: smart gadget applications showing their worth in practice', OT Practice, Vol. 17, No. 12, pp.9-12.

Wergin, R. and Modrykamien, A. (2012) 'Cognitive impairment in ICU survivors: assessment and therapy’, Cleveland Clinic Journal of Medicine, Vol. 79, No. 10, pp.705-712. 